\title{
Research on Ideological and Political Education in the Context of New Media
}

\section{Zhang Tao}

Ideological and Political Department of Xi 'an Aeronautical University, 710077, China

Keywords: ideological and political education, new media

\begin{abstract}
New media has a profound effect on people's thinking and behavior. In the context of new media, the infectivity, penetration and affinity of undergraduate ideological and political education have increased. But at the same time, educational content is weakened by new media, educational methods are not suitable for virtual spaces, undergraduates cannot adapt to the information society, and educators lack media literacy. It is necessary to enhance the ideological and political education of college students by enhancing the attraction of educational content in new media information, deepening the integration of educational methods and the characteristics of virtual space information dissemination, improving the ability of college students to adapt to the information society, and improving the media literacy of educators.
\end{abstract}

\section{Introduction}

The so-called new media is positioned relative to the traditional media. New media is a concept of time. It is a form of media within a certain period of time. New media technology is a technology marked by blogs, instant messaging tools, and streaming media. With the rapid development of information technology, the methods of accepting information by college students are characterized by diversity, openness, and timeliness. The ideological and political education environment for college students has become particularly complicated. New media technologies that use network communication tools as the mainstream have given students ideological and political education. Education presents a situation where opportunities and challenges coexist. Therefore, the study of college students' ideological and political work under the background of new media is of great significance for enriching the university students' ideology and theory and cultivating students' good moral character.

\section{Opportunities for Ideological and Political Education under the Background of New Media}

The extensive use of new media technologies has provided new ways, new carriers, and new channels for the development of ideological and political education in higher vocational education. It has provided richer content information, more convenient communication methods, more efficient solutions, and improved thinking.

It is conducive to the innovation of ideological and political education in higher vocational education. The advanced nature of the new media collection tools, the openness of the main body, and the sharing of information all put a new ideological and political education platform. In the era of new media, the information dissemination path has changed from one-dimensionality to multi-degrees, from single-dimension to multi-dimensions, and the spread of content from static to dynamic, and from singleness to diversification, the transmission and distribution of information has become more liberal, and the acceptance and application of information have become more conveniently, people can use the new media tools for unlimited time, unlimited geographical use, freely browse, forward, retrieve, download, access to information and enjoy services, rely on digital technology, network technology, and mobile communication technology to obtain information. In this process, the limitations of traditional ideological and political education carriers in terms of space, time, resources, and resources are solved. Students can break through the limitations of classroom and real-life 
resources and obtain new knowledge and information through various new media tools. It is possible to conduct ideological and political education more effectively. On the other hand, ideological and political educators can use mobile phones, networks, digital media, instant messaging software, and other new media tools to obtain richer instructional resources and forms of information representation, construct education models with care, and more easily filter and express educational content. Combine words with sounds, images, and data to disseminate advanced ideological theories and strengthen the radiation power of ideological and political education, providing an unprecedentedly powerful theoretical and practical platform for ideological and political education.

It is conducive to enriching the contents of ideological and political education in higher vocational schools. The extensive use of new media technologies has made the ideal mode of "everyone facing everyone" become a reality. Its dissemination content, communication needs, and ubiquitous and pervasive subjects are ubiquitous. It is an infinite world. The high openness and sharing characteristics of new media provide rich material and resources for the development of ideological and political education in higher vocational education. The extremely rich educational and teaching resources carried by the new media allow ideological and political educators to elicit sensible and time-sensitive data and enrich and improve educational texts. As an important social tool for college students, the new media also plays an important role as media and media in ideological and political education activities. It helps teachers to select targeted content among vast amounts of information resources, and develop edutainment and lively waves. Teachers' use of new media tools to communicate with students in different media spaces can greatly increase the interaction of ideological and political education in higher vocational education and make the content of ideological and political education more plentiful and comprehensive. It is also the development and improvement of ideological and political education in higher vocational education. A new model has been provided to increase the amount of resources and increase the value of resources, to enrich educational content, change the form of education, and enhance the effectiveness of education.

It is helpful to enhance the effectiveness of ideological and political education in higher vocational education. The emergence of new media technologies and the widespread use of new media transmission methods have opened up the barriers between the real world and the virtual world. They have brought about revolutionary changes in human production, lifestyle and social interaction. The student groups in higher vocational colleges are exactly Active participants and direct beneficiaries of this change. With the help of instant messaging software such as We-Chat and Wei-blog and the highly active and hidden nature of the interpersonal community, higher vocational ideological and political educators are more likely to walk into the spiritual world of college students and provide a smooth channel for teachers and students to communicate with each other, broadening the carrier. It has enriched the forms and made it possible to make the ideological and political work in higher vocational schools more targeted, so as to understand the students' true thoughts and ideological dynamics, thereby improving the pertinence and effectiveness of ideological and political work.

It is conducive to promoting the overall development of individual students in higher vocational schools. As a new social existence, the new media is widely used in all aspects of the education implementation process. It is not only a part of the advanced material culture of the society, but also one of the key elements of constructing and optimizing the overall environment of the ideological and political education in higher vocational colleges. The new media provide important means for higher vocational students to acquire knowledge and nutrition, broaden their horizons, accumulate culture, and enhance their own quality. It is also a bridge for them to communicate with society and one of the main tools for communicating with others. Through the new media platform, they can quickly understand the latest information at home and abroad, pay attention to the latest trends in social trends of thought, constantly absorb knowledge and nutrition, increase exchanges, increase knowledge, increase talents, and constantly improve their overall quality and capabilities. The new media has greatly enriched and expanded the space for ideological and political education, enabling people from different regions, different identities, and different strata to communicate and communicate with each other and jointly promote the continuous improvement and overall development of higher vocational students' quality through multiple channels. 


\section{Problems in Ideological Education under the Background of New Media}

From the phenomenon of the ideological and political education of college students in the new media, there are many problems in the main body of new media communication. The main manifestations are as follows: First, the ability of new media application themes to use new media to communicate and interact with each other is poor. The new media communication subject should use the new media technology to communicate the basic quality of the application theme, and should have a wealth of communication skills to use the new media technology to effectively communicate with college students. However, the quality of the application of the new media is not high and it will cause serious communication barriers in the communication process, affecting the bidirectionality of education. Second, the ideological quality of some application subjects is not high. If the main body of political ideological education for students on the new media platform cannot correctly apply Marxism to analyze and solve problems, it cannot transmit social positive energy, and it cannot combine the actual conditions of our country to guide students correctly. Then the students are in the new media. The platform will not be able to meet the precious resources of their thinking and growth. They will not be able to master the scientific problem solving methods and attitudes to life, and they will be unable to form the correct outlook on life, world outlook and values. The effect of using new media to ideological and political education for college students cannot be discussed. Third, the professionalism of some new media workers is poor. College students are excellent young people with certain ideological qualities and independent thinking skills. They have an active mindset but weak self-control abilities and are easily affected. If the new media staff is not high professional quality, they are in the form of psychological counseling or career planning and other kinds of teaching in the students, it is easy for students to question the columns on the new media platform, is not conducive to students thinking Political education, therefore, teachers should give full play to the exemplary role in the new media.

University students as an important role in the new media communication, the phenomenon that the participation consciousness is not strong are still a big problem in the current new media in college students' political and ideological education. New media is to provide a platform for college students and educators to communicate and interact. To fully play the role of a bridge, it also requires the active participation of students. However, from the perspective of college students' understanding and use of new media, there are two main reasons for their low participation. One is that new media is a virtual space. They are unwilling to express their own ideas and create communication barriers. The other reason is that the new media remains at a shallow level and does not really feel the value and fun of the new media, creating an obstacle to interaction.

New media have entered people's lives and become an important channel for people to obtain information because of their vast amount of information. As a resource for college students' ideological and political education in the new media, we must use Marxist perspectives, positions, and methods to analyze problems and solve problems, and to screen out information that is targeted, timely, and consistent with China's social development as an educational resource. However, due to the timeliness and lack of specificity of information in new media, the timeliness of communication is not strong. The outdated contents and backward viewpoints of some colleges and universities' new media platforms cannot fully meet the needs of students' growth and social development.

\section{Analysis of Countermeasures to Innovate Ideological and Political Education in the New Media Environment}

Under the background of new media, traditional education concepts and teaching methods and methods can be said to be totally incapable of adapting to the development of ideological and political education. To this end, the majority of ideological and political educators must further change their ideas and integrate student-centered teaching ideas into ideological and political education. In the teaching, the enthusiasm of the students is fully mobilized, an equal dialogue and exchange mechanism between the teacher and the student is established, and the autonomy of study in the 
process of teaching activities for higher vocational college students is respected. At the same time, it attaches great importance to the construction, application, and management of new media technologies. While striving to learn new media technologies, it will make full use of new media technologies, respect students' subjective awareness, and encourage students to communicate boldly and express their true ideas. When there are disagreements, it is necessary to communicate and dialogue on an equal basis until an agreement is reached.

The new media technology is a double-edged sword. We should abandon its disadvantages and use its advantages. Teachers and students in higher vocational colleges should improve their media literacy and grasp the initiative of ideological and political education. Specifically speaking, as vocational college students need to improve their ability to identify, select, judge, and reflect on various information network content and they do not sink into the quagmire of the Internet, affect their own physical and mental development, and do not disseminate information illegally on the Internet. And harmful information, strengthen the awareness of laws and regulations involved in new media technologies; as ideological and political education workers in higher vocational colleges, they should actively adapt to new media, improve their ability to control new media technologies, use new media technologies to enhance active communication and exchange with students, and keep abreast of The student's ideological status, at the same time, through activities such as knowledge lectures, community activities, and new media technology experience, helps the vocational college students to popularize new media knowledge and develop their media criticism capabilities, so as to positively guide students and arouse students' inner resonance and ideological conflicts. Finally, it will disseminate advanced positive energy to students and firmly grasp the initiative of ideological and political education.

Broadening educational approaches and innovating ideological and political education contents and methods under the background of new media, the ideological and political education of higher vocational college students will be exposed to all kinds of propaganda content. Therefore, ideological and political theory courses must incorporate new media technologies and adopt new media technologies. The physical and mental characteristics of contemporary college students are targeted to teaching, and politicians and political educators can also establish their own "blogs" to timely publish positive opinions and attitudes on international and domestic politics and public opinion, and they can also regularly update ideological and political education work. The person's experience and understanding of life guides the students of higher vocational colleges to advance towards real, good, and beautiful life realms.

\section{Conclusion}

To cope with the opportunities and challenges that ideological and political education of higher vocational students are facing in the context of new media, we must boldly open up new ideas, constantly improve methods, strengthen carrier construction, optimize resource platforms, and fully grasp the laws of ideological and political education under new media. Only in this way can higher vocational students' ideological and political education be more modern and scientific and effective.

\section{References}

[1] Zhu Jiansong. The Innovation of Ideological and Political Education in Colleges and Universities under the New Media Environment [J]. Journal of Southwest Jiaotong University (Social Science Edition), 2014, (5): 92.

[2] Ji Haiju. Study on Ideological and Political Education in Colleges and Universities in the New Media Age [D]. Nanjing Normal University, 2013.175

[3] Cai Jinyu. Research on Ideological and Political Education in Colleges and Universities under the Background of New Media [J]. Journal of Anshun University, 2015, (5):58.

[4] Wu Junqing. Some thoughts on strengthening college network ideological and political education 
[J]. China Higher Education Research, 2003, (5): 26.

[5] Zhao Yang. Thinking about the Innovation of College Students' Ideological and Political Education under the Background of New Media [J]. Research in Ideological Education, 2011, (12): 74. 